\title{
ANALISIS TUGAS ROOM ATTENDANT DALAM MENANGANI COMPLAINT TAMU DELUXE ROOM THE HAVEN SUITES CANGGU
}

\author{
Made Handijaya Dewantara \\ Email: handi.dewantara@pib.ac.id \\ POLITEKNIK INTERNASIONAL BALI
}

\begin{abstract}
ABSTRAK
Masalah yang diteliti adalah tugas dan tanggung jawab room attendant, standar operasional prosedur, dan penanganan complaint tamu di deluxe room The Haven Suites Canggu. Metode yang di gunakan ialah analisis deskriptif. Data yang diperoleh disusun dalam bentuk laporan. Berdasarkan hasil observasi ini dapat disimpulkan bahwa tugas dan tanggung jawab room attendant di deluxe room The Haven Suites Canggu sudah dilaksanakan sesuai dengan standar operasional prosedur (SOP) yang dibagi menjadi dua shift yaitu morning shift dan evening shift yang mempunyai tugas yang sedikit berbeda. Room attendant sudah melaksanakan standar operasional prosedur yang di terapkan di The Haven Suites Canggu. Cara menangani dan menyelesaikan complaint tamu di The Haven Suites Canggu berbeda tergantung dari jenis complaint
\end{abstract}

Kata Kunci: Petugas Kebersihan Kamar, Komplain, Kamar Deluxe

\begin{abstract}
The problem is how meticulous the duties and responsibilities of the room attendant, standard operational procedures, and handling guest complaint in deluxe room The Haven Suites Canggu. Author uses descriptive analysis. Data obtained in the form of a report compiled in. Based on the results of observation it can be concluded that the task and responsibility of the room attendant in the deluxe room The Haven Suites Canggu already carry it out in accordance with standard operational procedures (SOP) which is divided into two shifts, morning and evening shift which has a slightly different task. Room attendant has been applying standard operating procedure at the The Haven Suites Canggu. Guest complaint handling in deluxe room The Haven Suites Canggu how to deal with and resolve the complaint vary slightly in view of the type of complaint.
\end{abstract}

Keywords: Room Attendant, Complaint, Deluxe room 


\section{PENDAHULUAN}

Semenjak konferensi dunia dalam bidang lingkungan hidup (Globe'90) di Vancouver Kanada, para pemilik kepentingan atau stakeholders dalam bidang pariwisata mulai menaruh perhatian terhadap pentingnya pembangunan pariwisata dalam hal pelayanan kepada wisatawan. Data pertumbuhan pariwisata dunia tahun 1960an sebagaimana dipublikasikan oleh World Tourism Organization (WTO) setiap tahunnya menarik perhatian banyak negara atau daerah untuk mengembangkan pariwisata sebagai salah satu alternatif dalam meningkatkan kinerja pembangunan di negara atau daerah masingmasing. Ada beberapa daerah yang dilaporkan mengalami banyak kegagalan dalam pembangunan pariwisata dikarenakan kurangnya perhatian dan arti penting keberlanjutan (sustainability) karena terlalu berorientasi kepada target berupa angka-angka pertumbuhan yang harus dicapai, sehingga kurang memperhatikan aspek-aspek yang berkaitan dengan pelestarian lingkungan dan keberlanjutan aktivitas pariwisata.

Penilaian terhadap pariwisata oleh banyak pihak merupakan salah satu alternatif pembangunan, terutama bagi negara atau daerah yang memiliki keterbatasan sumber daya alam. Guna memaksimalkan dampak positif dari pembangunan pariwisata dan menekan serendah mungkin dampak negatif yang ditimbulkan dari pembangunan, maka diperlukan perencanaan yang bersifat terstruktur dan tertata. Pengembangan pariwisata dipergunakan oleh banyak pihak sebagai landasan dalam mengembangkan aktivitas/kegiatan di bidang masing-masing. Bahkan, pengembangan yang dimaksud harus berkolaborasi dengan rencanarencana pembangunan pada sektor-sektor yang lainnya dan tetap menjaga konsisten dengan rencana pembangunan kepariwisataan nasional secara keseluruhan. Pariwisata merupakan aktifitas yang sangat kompleks, bersifat multi sektoral dan terfragmentasikan, karena itu dibutuhkan 
koordinasi antar berbagai sektor terkait yaitu melalu proses perencanaan yang tepat. Perencanaan juga diharapkan dapat membantu tercapainya kesesuaian antara ekspektasi pasar yang diharapkan dengan produk wisata yang dikembangkan tanpa harus mengorbankan kepentingan antara pihak yang bersangkutan. Mengingat masa depan yang tidak luput dengan perubahan, maka perencanaan yang baik diharapkan dapat memberikan dampak yang baik juga terhadap perubahan-perubahan lingkungan strategis dan menghindari sejauh mungkin dampak negatif yang ditimbulkan oleh perubahan yang terjadi di masa depan.

Menurut penuturan website TripAdvisor tahun 2017, Bali sebagai destinasi wisata yang paling digemari tamu mancanegara. Prestasi Bali sebagai destinasi favorit terlihat dari jumlah kunjungan wisatawan mancanegara dari tahun ketahun terus bertambah. Berdasarkan data Dinas Pariwisata Provinsi Bali (2017), pada tahun 2013 jumlah kunjungan wisatawan mancanegara yaitu 3,27 juta (mengalami kenaikan 13,1\%). Pada tahun 2014 jumlah kunjungan wisatawan mancanegara adalah 3,67 juta (mengalami kenaikan 14,9\%). Pada tahun 2015 jumlah kunjungan wisatawan mancanegara adalah 4 juta (mengalami kenaikan 6,3\%). Pada tahun 2016 jumlah wisatawan mancanegara mengalami kenaikan yang sangat signifikan menjadi 4,92 juta (mengalami kenaikan 23,14\%). Pada tahun 2017 jumlah wisatawan mancanegara menjadi 5,96 juta (mengalami kenaikan 21,1\%)

Salah satu pendukung kegiatan/aktifitas pariwisata dalam melayani wisatawan adalah hotel. Hotel merupakan sarana pendukung dalam dunia pariwisata. Terutama dalam suatu destinasi, sangat pentingnya keberadaan hotel merupakan salah satu faktor apakah destinasi tersebut diminati atau tidak. Hotel merupakan bentuk dari akomodasi wisata. Salah satu jasa perhotelan di Bali adalah The Haven Suites Canggu terletak di tengah kota yang mempermudah para pebisnis dan turis untuk 
melakukan kegiatannya, oleh sebab itu arus dari perputaran check incheck outnya sangatlah cepat. Seorang room attendant memiliki tanggung jawab dan dituntut untuk cepat dan teliti dalam membersihkan dan menyiapkan kamar yang dijual, apabila terjadi kesalahan, tamu biasanya akan merasa kecewa pada kamar yang disiapkan dan tamu akan complaint.

Departemen house keeping atau dalam Bahasa Indonesia tata graha dalam suatu organisasi hotel memegang peranan penting untuk menunjang kelancaran bisnis suatu hotel. Bertugas di house keeping berarti harus siap menerima dan menghadapi berbagai masalah yang timbul kedepannya, karena tugas-tugas house keeping bersifat kompleks. Permasalahan yang timbul bermacam-macam, mulai dari permasalahan produk pelayanan, pribadi karyawan, perilaku tamu dan karyawan, keamanan, tamu tidak mendapatkan kamar, maupun masalah-masalah yang berkaitan dengan kualitas dan kebersihan produk yang di pakai oleh tamu.

House keeping/tata graha berasal dari kata house yang berarti rumah dan keeping (to keep) yang berarti memelihara, merawat, atau menjaga. House keeping atau tata graha adalah bagian atau departemen yang mengatur atau menata peralatan, menjaga kebersihan, memperbaiki kerusakan, dan memberi dekorasi dengan tujuan agar rumah (hotel) tersebut tampak rapi, bersih, menarik dan menyenangkan bagi penghuninya. Berdasarkan pendapat Brason dan Lennox (Agusnawar, 2000: 20), house keeping domestic administration or accomodation service is therefore essential in all type be comfort, cleanleness and service in all this should be the concert of every member of the estabilishment. Jelas bahwa house keeping, adalah bagian administrasi rumah tangga atau layanan akomodasi merupakan hal yang sangat diperlukan oleh hotel-hotel, klub-klub, rumah sakit, atau asrama, dan 
layanan serta semuanya harus menjadi perhatian atau tanggung jawab setiap orang atau staf.

Melihat dari arti kata house keeping itu maka peran house keeping department sangat penting di dalam hotel. House keeping department dan front office department tidak dapat dipisahkan satu dengan yang lain karena keduanya sangat menunjang keberhasilan dari hotel tersebut. Memang tidak dapat dipungkiri bahwa hubungan antara House keeping department dan front office department mempunyai hubungan yang sangat erat karena house keeping department yang mempersiapkan kamar-kamar yang akan dijual beserta fasilitas yang diperlukan dan front office department menjual kamar-kamar, maka dapat disebut dengan room devision.

House keeping departement mempunyai tugas dan tanggung jawab atas seluruh areal hotel, baik yang berada di dalam gedung kamar-kamar, ruangan-ruang yang disewa seperti drugstore, barber shop, beauty salon, money change, fitnescentre, meeting room, travel agent, restaurant, locker maupun di luar kamar (Kebun/taman, kolam renang, tennis court). Secara garis besar dapat disimpulkan bahwa house keeping ini adalah sebagai kepala rumah tangga, sebagaimana rumah tangga dirumah, mempunyai tanggung jawab untuk memberikan: 1) kesegaran, 2) ketenangan, 3) keamanan, 4) kenyamanan, 5) kepuasan.

Struktur organisasi house keeping adalah proses pengelompokan seksi-seksi, tugas, dan tanggung jawab atau wewenang sedemikian rupa sehingga tercipta suatu organisasi yang dapat digerakkan sebagai satu kesatuan untuk mencapai tujuan yang telah ditentukan. Dengan adanya pengelompokan seksi-seksi yang jelas, setiap karyawan bagian house keeping dapat mengetahui dengan pasti bidang pekerjaan, atasan, dan tanggung jawabnya. 
Guna menunjang kelancaran tugas sehari-hari, house keeping dibagi menjadi beberapa bagian sesuai dengan areal tugas masingmasing. Dengan demikian house keeping dapat dibagi menjadi beberapa bagian diantaranya: 1) Floor Section (attendant), 2) Houseman Section (Public Area Section), 3) Linen Section, 4) Laundry Section. Salah satu bagian dalam house keeping adalah room attendant. Yuaniarsih (2016) mengungkapkan bahwa Room attendant bertanggung jawab terhadap inventaris, pembersihan dan pengawasan ruangan kamar-kamar tamu yang akan dijual atau disewakan kepada tamu.

Seorang room attendant harus memiliki skill dan ketelitian dalam mengerjakan tugasnya, karena apabila terjadi keteledoran dari segi pembersihan kamar atau mengisi kelengkapan, maka tamu akan merasa kurang nyaman dan komplain. Seorang room attendant harus mempunyai kepekaan dan ketelitian dalam membersihkan kamar tamu, karena apabila dalam pembersihan kamar tidak teliti maka akan membuat citra hotel tersebut buruk. Hal ini juga dapat mengakibatkan tamu yang telah loyal terhadap hotel pindah ke hotel lain karena cara penangannya yang kurang cepat dan serius. Menurut Hoyer dan Ridgway (1984) dalam Setiyaningrum (2007: 105) bahwa ketidakpuasan konsumen terhadap merek produk layanan atau jasa yang digunakan merupakan faktor yang menyebabkan terjadinya perpindahan merek. Ketidakpuasan konsumen ini terjadi sebagai akibat dari produk atau merek yang di gunakan sebelumnya tidak sesuai dengan keinginan atau harapan konsumen.

Mengingat peran room attendant yang sangat penting, maka peneliti tertarik untuk mengambil judul Tugas Room attendant dalam Menangani Complaint Tamu Deluxe Room di Hotel The Haven Suites Canggu. Berdasarkan latar belakang yang telah diungkapkan, adapun permasalahan yang diangkat dalam penelitian ini yaitu sebagai berikut: 1) Bagaimana tugas dan tanggung jawab room attendant di deluxe room 
Hotel The Haven Suites Canggu? 2) Bagaimana Standar Operasional Prosedur (SOP) di deluxe room Hotel The Haven Suites Canggu? 3) Bagaimana penanganan complain tamu di deluxe room hotel The Haven Suites Canggu?

\section{KONSEP DAN TEORI}

Lebih lanjut pada bagian ini akan dipaparkan mengenai konsep dan teori yang digunakan dalam penelitian ini

\subsection{KONSEP ROOM ATTENDANT}

Menurut Agusnawar (2000: 22), House keeping merupakan bagian yang bertugas memelihara kebersihan, kerapian, dan kelengkapan kamar, restoran, bar, tempat-tempat umum dalam hotel dan tempattempat untuk karyawan, kecuali tempat-tempat yang sudah menjadi tugas dan tanggung jawab steward seperti kitchen area, diswashing area, dan garbage area. Room attendent ialah bagian dari Housekeeping yang bertugas menjaga kebersihan, kerapian, kenyamanan, dan kelengkapan kamar-kamar hotel. Room attendant harus memiliki penampilan baik dan rapi meliputi tingkah laku kejujuran, sopan santun pada tamu, atasan, teman, dan sejawat. Petugas pria disebut Room Boy sedangkan petugas wanita disebut Room Maid. Pihak tata graha khususnya seksi kamar juga dituntut untuk memberikan pelayanannya yang istimewa kepada tamu melalui room attendant agar tamu merasa puas selama tinggal di hotel dan diharapkan dapat menjadi pelanggan hotel.

Room Boy atau Room Maid adalah seorang petugas hotel yang membersikan, merapikan kamar-kamar tamu menjadi indah, nyaman dan lengkap. Dalam membersihkan dan memelihara kamar hotel agar dapat dijual dan memuaskan para tamu, Room Boy harus mempunyai peranan penting bagi kelancaran, kebersihan, dan pemasukan hotel, dengan kata lain hidup matinya suatu hotel tidak menerima pelayanan yang 
memuaskan, maka tidak menutup kemungkinan bahwa tamu tersebut akan menceritakan kekecewaannya pada orang lain sehingga memeperkecil jumlah tamu yang datang untuk menginap di hotel tersebut. Oleh sebab itu peranan sangat penting dalam menjaga kebersihan, kerapian, keindahan, kenyaman kamar hotel agar tamu-tamu merasa senang dan puas akan pelayanan hotel tersebut.

\subsection{KONSEP COMPLAINT TAMU}

Lie Gabriel Wantah (1998) mendefinisikan bahwa complaint atau keluhan merupakan bentuk ketidakpuasan tamu terhadap fasilitas atau pelayanan yang tidak sesuai. Keluhan tamu bisa di sikapi dari segi positif yang artinya dengan adanya keluhan tersebut, karena sebuah hotel dapat menilai sejauh mana kualitas pelayanan yang di berikan kepada tamu, karena pelayanan yang di berikan akan di harapkan dapat menjadi tolak ukur dalam komitmen dalam memajukan hotel secara keseluruhan.

\subsection{DELUXE ROOM}

Sugiarto (1996: 28) menjelaskan Deluxe/Superior Room merupakan jenis penamaan untuk kamar yang setingkat lebih baik dari standard room, dengan fasilitas yang sama dengan kamar standar. Hal yang membuatnya lebih baik adalah: a) Letak kamar strategis, b) Arah kamar lebih baik pemandangannya, c) Mutu bahan untuk mebelair dan perabotan lebih baik dari kamar standar, d) Ukuran kamar lebih luas dari kamar standar

Berdasarkan konsep yang telah diuraikan, penelitian ini berupaya untuk menganalisis tugas dan tanggung jawab room attendant, Standar Operasional Prosedur (SOP) dan cara penanganan complaint tamu di deluxe room hotel The Haven Suites Canggu. 


\subsection{TEORI SOP PEMBERSIHAN KAMAR ROOM ATTENDANT}

Penelitian ini menggunakan teori SOP pembersihan kamar oleh Room Attendant oleh Agusnawar (2004). Room attendant merupakan petugas hotel yang berada pada seksi kamar yang berhubungan langsung dengan tamu (front of the house). Tugas dari room attendant dapat dikatakan rumit dan berat karena complaint yang datang dari tamu banyak sekali hubunganya dengan kamar dan baik atau buruknya kamar hotel tergantung dari kualitas room attendant hotel tersebut. Harus diingat, bahwa ketika tamu masuk kamar, pandangan pertamanya akan ditunjukkan pada kerapian tempat tidur. Kesan pertama atas hotel secara keseluruhan hanya dengan melihat kerapian tempat tidur. Berikut diuraikan tugas dan tanggung jawab room attendant dalam pelayanan:

a) Mengelola kamar. Baik atau buruknya kamar sangat tergantung pada room attendant, mulai dari ketelitian, kerajinan maupun kualitas. Room attendant harus rajin dan mampu mengerjakan kamar, teliti dan terampil dalam memeriksa semua perlengkapan yang ada di dalamnya sehingga akan dapat menghasilkan kamar yang bersih, rapi, lengkap dan nyaman.

b) Melayani tamu. Agar tamu dapat merasa puas maka room attendant harus dapat memeberikan pelayanan yang berkualitas. Di dalam memberikan pelayanan kepada para tamu tidak dibatasi waktunnya, sebab setiap saat tamu dapat meminta pelayanan, baik pagi, siang, sore, maupun malam hari. Pelayanan adalah suatu usaha yang dilakukan oleh manusia, untuk manusia, dalam memenuhi kebutuhan serta tujuan sehingga mampu membuat tamu merasa puas.

c) Menjalin kerja sama dengan sesama room attendant dan seksi - seksi lain yang berada di housekepping department, bahkan dengan seksi yang berada didepartment lain. Hal ini perlu dilaksanakan karena industri hotel merupakan satu kesatuan yang tidak dapat dipisahkan 
yang terdiri dari beberapa department yang masih memiliki hubungan yang erat dan tidak dapat berjalan dengan sendirinya. Untuk melaksanakan tugas pelayanannya, room attendant dalam kesehariannya dibagi menjadi tiga shift dalam pelaksanaannya, yaitu:

Morning Shift :Pukul $08.00-16.00$

Evening Shift :Pukul $16.00-00.00$

Night Shift :Pukul $00.00-08.00$

Standard operating procedure make up room menurut Agusnawar dalam bukunya Tata Graha (2004: 42)

a) Mendorong trolley ke depan pintu, mengetuk pintu sebanyak 3 (tiga) kali sambil mengucapkan identitas, bila tidak ada jawaban buka pintu perlahan-lahan

b) Periksa seluruh ruangan barangkali ada barang tamu yang tertinggal, jika ada laporkan ke Housekeeping office.

c) Periksa keadaan semua lampu, AC, televisi, dan mini bar apabila ada kerusakan hubungi langsung Handyman/Engenering.

d) Membuka night curtain dan membuka jendela

e) Melakukan stripping sampai seluruh ruangan baik yang terdapat pada asshtray maupun yang berserakan di lantai lalu buang ke garbage humper yang ada di trolley, dan stripping gelas, cangkir dan sendok teh, lalu rendam dengan air panas di washbahsin

f) Stripping linen kotor yang terdapat di kamar maupun di kamar mandi

g) Proses making bed.

h) Membersihkan kamar mandi

i) Lengkapi guest supplies untuk di kamar tempat tidur.

j) Dusting seluruh furniture yang ada di dalam kamar dengan menggunakan dust cloth dan chemical

k) Vacuum seluruh ruangan dimulai dan sudut yang terjauh dari pintu sampai keluar kamar 
1) Memeriksa semua kelengkapan guest supplies baik yang ada di bath room maupun yang ada di kamar

m) Tutup jendela, rapihkan night curtain, hidupkan AC dan TV semprotkan air freshner di dalam ruangan

n) Setelah semua lengkap dan bersih melakukan pengecekan kembali apakah sudah benar-benar bersih dan tidak meniggalkan sampah lagi.

o) Tutup pintu

p) Mengisi room boy control sheet

\section{METODE PENELITIAN}

Penelitian ini merupakan penelitian deskriptif kualitatif. Metode deskriptif adalah metode yang digunakan untuk meneliti status kelompok manusia, suatu objek, suatu kondisi dan suatu sistem pemikiran serta peristiwa yang akan terjadi.Pendekatan deskriptif kualitatif digunakan untuk menggambarkan, menguraikan, dan menjelaskan secara sistematik mengenai fakta-fakta, sifat-sifat, serta hubungan antara berbagai gejala yang akan diteliti. Berdasarkan pemikiran tersebut dan dengan menggunakan metode observasi, melakukan wawancara mendalam dan dan studi dokumentasi, dideskripsikan apa yang terjadi dan mendapatkan fakta-fakta yang terkait dengan peran room attendant dalam menghadapi complain tamu.

Dalam penelitian, disamping menggunakan metode yang tepat di butuhkan juga ketepatan dalam melihat dan menyusun teknik pengumpulan data yang relevan. Secara umum, tujuan pengumpulan data adalah untuk memperoleh fakta-fakta yang di perlukan untuk mencapai tujuan penelitian yang telah dirumuskan. Adapun beberapa teknik pengumpulan data yang digunakan dalam penelitian ini adalah sebagai berikut. 
a) Observasi (pengamatan). Menurut Satori (2010: 104-105) mengatakan bahwa Pengertian observasi kualitatif adalah pengamatan langsung terhadap objek, situasi, konteks dan maknanya dalam upaya mengumpulkan data penelitian. Peneliti melakukan pengumpulan data dengan turun langsung ke lokasi penelitian dan mengamati permasalahan yang terjadi di lapangan.

b) Wawancara. Peneliti menggunakan teknik ini kepada sebagian karyawan dan staff yang ada di The Haven Suites Canggu, Bali.Wawancara adalah Teknik pengumpulan data dengan cara tanya jawab sambil bertatap muka antara sipenanya dengan pewawancara dengan menggunakan alat yang dinamakan Interview Guide (panduan wawancara).

c) Studi Kepustakaan yaitu dengan mendapatkan informasi dan datadata tambahan melalui bahan-bahan tertulis di The Haven Suites Canggu, Baliseperti melalui buku-buku, brosur dan dokumen lain. Disamping itu peneliti juga membaca buku-buku yang ada hubungannya dengan judul pokok masalah. Menurut Arikunto (2006: 166) Studi Pustaka adalah pengumpulan data dengan cara mencari informasi melalui buku-buku, Koran, majalah dan literature lainnya.

d) Dokumentasi. Peneliti melakukan kegiatan dokumentasi yang di maksudkan untuk memperoleh berbagai data tertulis dan gambar yang relevan dengan penelitian yang dilakukan

\section{GAMBARAN THE HAVEN SUITES BALI}

The Haven Suites Bali terletak di Canggu di Daerah Bali, 5 menit berkendara dari Pantai Echo, serta memiliki suite dengan perabotan kayu dan sentuhan Bali. Akomodasi ini menyediakan kolam renang luar ruangan yang luas dan kolam renang anak-anak. Pengunjung dapat menikmati hidangan di restoran. Setiap kamar dilengkapi dengan TV 
satelit. Unit-unit tertentu memiliki area tempat duduk untuk kenyamanan. Beberapa kamar juga menyuguhkan pemandangan laut atau kolam renang. Kamar mandi pribadi tersedia di semua kamar.

Di Hotel ini dapat menikmati sarapan setiap pagi dan bersantap di dalam kamar yang tersedia berdasarkan permintaan. Ketumbar Restaurant menyajikan pilihan hidangan Asia dan Internasional. Hotel ini juga menyediakan penyewaan sepeda. The Haven Suites Bali berjarak 900 meter dari Pantai Batu Bolong dan 1,4 km dari Pantai Echo, sedangkan Bandara Internasional Ngurah Rai terletak sejauh 10 km dari hotel.

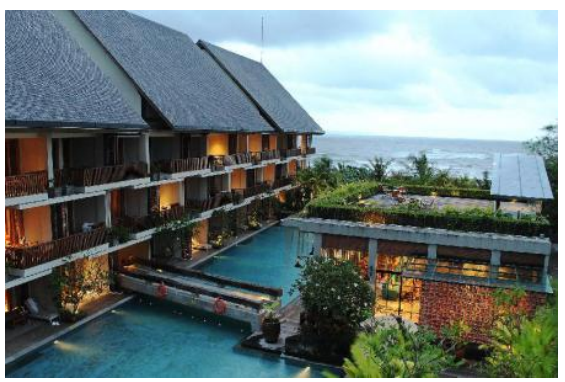

Gambar 1. Hotel The Haven Suites Bali https://id.hotels.com/ho624508/the-havensuites-bali-berawa-canggu-indonesia/

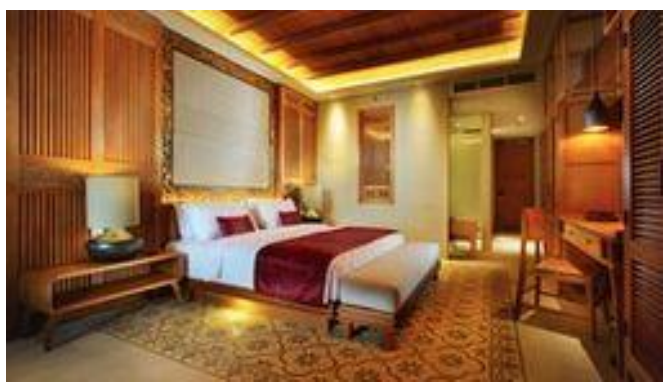

Gambar 2. Deluxe Room The Haven Suites Bali https://id.hotels.com/ho624508/the-haven-suitesbali-berawa-canggu-indonesia/

\section{PEMBAHASAN}

Pembahasan akan memaparkan jawaban dari masalah yang ada dalam penulisan ini, untuk lebih jelasnya dapat dilihat di bawah ini

\subsection{TUGAS DAN TANGGUNG JAWAB ROOM ATTENDANT DELUXE ROOM DI THE HAVEN SUITES CANGGU, BALI}

Room attendant merupakan bagian yang bertugas dalam hal pemeliharaan kamar hotel, untuk melaksanakannya dengan baik seorang room attendant harus mengetahui tugas dan tanggung jawabnya sebagai seorang room attendant. Room attendant bertanggung jawab terhadap pemeliharaan kamar tamu hotel, yang meliputi kebersihan, kerapihan, dan kenyamanan tamu di hotel. Selain itu, seorang room attendant dituntut 
untuk memberikan pelayanan prima dalam hotel penuh sehingga tamu merasa puas selama tinggal di hotel dan menjadi pelanggan tetap.

Adapun tugas dan tanggung jawab seorang room attendant di The Haven Suites Canggu, Bali dibagi menjadi dua shift dalam pelaksanaannya, yaitu morning shift pukul 8.00-16.00, dan evening shift pukul 15.00-23.00, tugas dan tanggung jawabnya pun berbeda yaitu:

\section{Morning Shift}

A. Persiapan. Pada tahap ini, room attendant melakukan persiapan sebagai berikut:

1) Melapor ke house keeping office dengan menandatangani daftar hadir (attendance record) pada kolom Time In.

2) Mengambil room assignment sheet yang merupakan daftar kamar-kamar yang harus dikerjakan oleh room attendant. Room assignment sheet ini dipersiapkan oleh floor supervisor untuk mengatur alokasi room attendant dalam pembersihan semua kamar di hotel.

3) Mengambil kunci kamar (Master key) sesuai dengan daftar kamar pada room assignment sheet kemudian menandatangani pada key log book pada kolom Key Out.

4) Mengikuti Morning briefing yang dipimpin oleh supervisor untuk mendapatkan informasi mengenai aktivitas hotel misalnya: EA, ED, VIP, dan lain-lain.

5) Room attendant menuju section masing-masing sesuai dengan lantainya kemudian mengambil trolley sebagai tempat penyimpanan semua peralatan penunjang kamar.

6) Mengecek semua kamar untuk memastikan status kamar sesuai dari sIstem komputer sama dengan status fisik. Selain itu, tujuan lainnya adalah mengecek laundry tamu, mengecek kamar yang 
ada tanda "SERVICE dan DND" dan mengisi room discrepancy yang diisi oleh room attendant.

7) Pengecekan fisik ini akan diambil oleh runner dan di laporkan ke bagian order taker untuk mengupdate status kamar.

8) Room attendant sudah siap melakukan pembersihan kamar. Biasanya akan dimulai dari kamar-kamar yang stay over

B. Pembersihan. Pada tahap ini, room attendant sudah mempersiapkan segala yang dibuthkan untuk membersihkan kamar tamu, Prosedur pembersihan yang dilakukan meliputi hal-hal sebagai berikut:

1) Entering the guestroom

a. Bell kamar kemudian sebutkan "House keeping", bila tidak ada respon ulangi lagi. Jika masih tidak ada respon, buka pintu perlahan sambil mengatakan house keeping.

b. Jika ada respon dari dalam, tunggu hingga pintu dibuka oleh tamu kemudian minta ijin apakah kamarnya dapat dibersihkan.

2) Begining Task

a. Bawa masuk cleaning kit dan linen bersih ke dalam kamar, letakkan cleaning kit ke bathroom dan linen diatas table guest.

b. Buka curtain supaya penerangan di dalam kamar lebih terang. Buka jendela untuk memberikan udara segar. Bawa gelas, astray, cangkir yang kotor ke pantry dengan menggantinya dengan yang baru, bila ada tray room service hubungi room service untuk pick up.

c. Bersihkan tempat sampah dan buang sampah tersebut ke rubbish bag 
d. Periksa semua ruangan untuk melihat apakah ada barangbarang tamu yang tertinggal.

3) Stripping the bed

a. Pindahkan bila ada barang/pakaian tamu ke tempat, setelah selesai making kembalikan ke posisi awal.

b. Lepaskan sarung bantal satu per satu kemudian letakkan bantal diatas meja/sofa.

c. Tarik sheet kotor satu per satu agar barang yang ada di bed tersebut tidak terbawa ke laundry.

d. Pindahkan semua linen kotor ke linen bag pada trolley.

4) Making the bed

a. Periksa kebersihan bed pad, ganti bila kotor.

b. Letakkan sheet pertama di tengah bed, kemudian kunci masing-masing sudutnya dengan membentuk sudut 45 derajat.

c. Letakkan duvet cover seperti sheet pertama, ujung atas duvet sejajar dengan tepi bed, kemudian rapikan hingga terlihat kencang.

d. Letakkan bantal yang sudah dipasang sarung bantal pada ujung bed dekat head board.

e. letakkan bed runner sebelah bawah dari bed

5) Cleaning the bathroom

a. Ambil Glass tumbler yang kotor kemudian simpan di pantry, dan ambil glass tubler yang bersih yang sebelumnya sudah di sediakan di setiap pantry.

b. Bersihkan toilet, bathtup, shower, basin dan mirror.

c. Ganti towel yang kotor dengan yang bersih sesuai dengan standar. 
d. Ganti dengan yang baru semua amenities yang dipakai. Letakkan sesuai dengan standar tipe deluxe room

e. Bersihkan lantai kamar mandi, pastikan bahwa rambut tidak ada yang tertinggal.

6) Dusting. Proses dilakukan secara arang jarum jam supaya tidak ada debu yang terlewatkan

7) Vacuuming the room. Vacuum lantai mulai dari area yang paling jauh dari pintu kemudian berjalan mundur. Pastikan semua permukaan lantai tidak ada yang terlewatkan.

8) Closing. Update data kamar bila selesai mengerjakan kamar di form work list dan menulis jumlah aminities dan linen apa saja yang di pakai oleh tamu di aminities and linen form.

\section{Evening Shift}

Tugas seorang room attendant pada evening shift tidak jauh berbeda dengan tugas morning shift hanya terdapat sedikit perbedaan yaitu:

\section{A. Persiapan}

Pada tahap ini, room attendant melakukan persiapan yang sedikit berbeda dengan morning shift yaitu:

1. Pertama kali datang mengikuti breafing dan menunggu perintah dari team leader.

2. Mengambil work sheet dan kunci kamar dilakukan ketika room atendant morning shift selesai mengerjakan kamar sampai pukul $4.00-05.00 \mathrm{pm}$.

3. Room attendant menuju section masing-masing dengan lantainya, kemudian mengambil trolley dan melengkapi aminities dan linen kebutuhan tamu dan siap membantu room attendant morning shift dalam mengerjakan kamar yang masih belum di kerjakan. 
4. Biasanya di mulai dengan kamar-kamar vacant dirty (VD) dan expected arrival (EA).

B. Pembersihan. Pada tahap ini, room attendant sudah siap membersihkan kamar tamu, prosedur pembersihan yang di lakukan meliputi hal-hal sebagai berikut :

1. Entering the guestroom

a) Bell kamar kemudian sebutkan "House keeping", bila tidak ada respon ulangi lagi. Jika masih tidak ada respon, buka pintu perlahan sambil mengatakan "house keeping".

b) Jika ada respon dari dalam, tunggu hingga pintu dibuka oleh tamu kemudian minta ijin apakah kamarnya dapat dibersihkan.

2. Begining Task

a) Bawa masuk cleaning kit dan linen bersih ke dalam kamar. letakkan cleaning kit ke bathroom dan linen diatas table guest.

b) Buka curtain supaya penerangan di dalam kamar lebih terang. Buka jendela untuk sirkulasi udara segar (beberapa hotel memiliki jendela yang tidak dapat dibuka dengan alasan keamanan). Selanjutnya, bawa gelas, astray, cangkir yang kotor ke pantry dan ganti dengan yang baru, bila ada tray room service hubungi room service untuk pick up.

c) Bersihkan tempat sampah dan buang sampah tersebut ke rubbish bag

d) Periksa semua ruangan untuk melihat apakah ada barangbarang tamu yang tertinggal. 
3. Stripping the bed

a) Pindahkan bila ada barang/pakaian tamu ke tempat, setelah selesai making kembalikan ke posisi awal.

b) Lepaskan sarung bantal satu per satu kemudian letakkan bantal diatas meja/sofa.

c) Tarik sheet kotor satu per satu agar barang yang ada di bed tersebut tidak terbawa ke laundry

d) Pindahkan semua linen kotor ke linen bag pada trolley.

4. Making the bed

a) Periksa kebersihan bed pad, ganti bila kotor.

b) Letakkan sheet pertama di tengah bed, kemudian kunci masingmasing sudutnya dengan membentuk sudut 45 derajat.

c) Letakkan duvet cover seperti sheet pertama, ujung atas duvet sejajar dengan tepi bed, kemudian rapikan hingga terlihat kencang.

d) Letakkan bantal yang sudah dipasang sarung bantal pada ujung bed dekat head board.

\section{Cleaning the bathroom}

a) Ambil Glass tumbler yang kotor kemudian simpan di pantry, dan ambil glass tumbler yang bersih yang sebelumnya sudah di sediakan di setiap pantry.

b) Bersihkan toilet, bathtup, shower, basin dan mirror.

c) Ganti towel yang kotor dengan yang bersih sesuai dengan standar.

d) Ganti dengan yang baru semua amenities yang dipakai. letakkan sesuai dengan standar tipe deluxe room

e) Bersihkan lantai kamar mandi, pastikan bahwa rambut tidak ada yang tertinggal. 
6. Dusting Proses. Dusting dilakukan secara arang jarum jam supaya tidak ada debu yang terlewatkan.

7. Vacuuming the room.Vacuum lantai dari area yang paling jauh dari pintu dengan cara berjalan mundur. Pastikan semua permukaan lantai tidak ada yang terlewatkan.

8. Closing Update data kamar bila selesai mengerjakan kamar di form work list dan menulis jumlah aminities dan linen apa saja yang di pakai oleh tamu di aminities and linen form.

9. Turn down. Pekerjaan evening shift yang di karenakan tidak terlalu banyak, maka pada saat selesai membantu room attendant morning shift. Room attendant evening shift kembali ke office house keeping sekitar pukul 4.00pm-5.00pm untuk mengambil work list yang berisi data-data kamar yang harus di pindahkan aminities dan linen untuk mempermudahkan tamu di dalam memakai fasilitas tersebut (turn down). Tugas yang harus di lakukan saat turn down yaitu:

a) Memindahkan botol air mineral dan satu long passion glass dekat meja kecil, fungsinya untuk mempermudah tamu bila ingin mengambil minum tidak perlu lagi beranjak dari tempat tidurnya.

b) Menutup tirai kamar

c) Memindahkan bath mat dari atas bath tub ke lantai dekat bath tub, fungsinnya untuk mempermudah tamu bila ingin mandi malam hari atau pagi hari tidak perlu menurunkannya sendiri.

d) Memindahkan remote televisi untuk mempermudah tamu jika ingin menonton televisi, tidak perlu lagi harus bangun dari tempat tidur. 


\subsection{SOP PEMBERSIHAN DELUXE ROOM DI THE HAVEN SUITES CANGGU, BALI}

Pada tahap standar operasional prosedur seorang room attendant sudah melakukan pengecekan kamar dan discreppancy dan siap untuk membersihkan kamar tamu deluxe room.

1. Entering the guestroom

a) Bell kamar kemudian sebutkan "House keeping", bila masih tidak ada respon ulangi lagi. Jika masih juga tidak ada respon, buka pintu perlahan sambil mengatakan "house keeping".

b) Jika ada respon dari dalam, tunggu hingga pintu dibuka oleh tamu kemudian minta ijin apakah kamarnya dapat dibersihkan.

2. Begining Task

a) Bawa masuk cleaning kit dan linen bersih ke dalam kamar. letakkan cleaning kit ke bathroom dan linen diatas table guest.

b) Buka curtain supaya penerangan di dalam kamar lebih terang. Buka jendela untuk sirkulasi udara segar (beberapa hotel memiliki jendela yang tidak dapat dibuka dengan alasan keamanan). Selanjutnya, bawa gelas, astray, cangkir yang kotor ke pantry dengan menggantinya dengan yang baru, bila ada tray room service hubungi room service untuk pick up.

c) Bersihkan tempat sampah dan buang sampah tersebut ke rubbish bag

d) Periksa semua ruangan untuk melihat apakah ada barang-barang tamu yang tertinggal.

3. Stripping the bed

a) Pindahkan bila ada barang/pakaian tamu ke tempat, setelah selesai making kembalikan ke posisi awal.

b) Lepaskan sarung bantal satu per satu kemudian letakkan bantal diatas meja/sofa. 
c) Tarik sheet kotor satu per satu agar barang yang ada di bed tersebut tidak terbawa ke laundry.

d) Pindahkan semua linen kotor ke linen bag pada trolley.

4. Making the bed

a) Periksa kebersihan bed pad, ganti bila kotor.

b) Letakkan sheet pertama di tengah bed, kemudian kunci masingmasing sudutnya dengan membentuk sudut 45 derajat.

c) Letakkan duvet cover seperti sheet pertama, ujung atas duvet sejajar dengan tepi bed, kemudian rapikan hingga terlihat kencang.

d) Letakkan bantal yang sudah dipasang sarung bantal pada ujung bed dekat head board.

5. Cleaning the bathroom

a) Ambil Glass tumbler yang kotor kemudian simpan di pantry, dan ambil glass tumbler yang bersih yang sebelumnya sudah di sediakan di setiap pantry.

b) Bersihkan toilet, bathtup, shower, basin dan mirror.

c) Ganti towel yang kotor dengan yang bersih sesuai dengan standar.

d) Ganti dengan yang baru semua amenities yang dipakai. Letakkan sesuai dengan standar tipe deluxe room

e) Bersihkan lantai kamar mandi, pastikan bahwa rambut tidak ada yang tertinggal.

a) Dusting Proses. Dusting dilakukan secara arang jarum jam supaya tidak ada debu yang terlewatkan, yaitu mulai dari: a) Bed table, b) Heard board, c) Work table, d) Televisi (LED), e) Mirror, f) Lemari sepatu dan lemari pakaian, g) pintu

6. Vacuuming the room. Vacuum lantai dari mulai dari area yang paling jauh dari pintu dengan cara berjalan mundur. Pastikan semua 
permukaan lantai tidak ada yang terlewatkan, bagian-bagian yang harus di vacuum yaitu: a) Karpet, b) Bawah bed, c) Lantai bathroom, d) Lantai luar bathroom, e) Sela-sela sofa bed, f) Karpet luar deluxe room

7. Closing Update data kamar bila selesai mengerjakan kamar di form work list dan menulis jumlah aminities dan linen apa saja yang di pakai oleh tamu di aminities and linen form yang harus dilakukan di lakukan oleh room attendant yaitu:

a) Update data kamar seperti dari vacant dirty menjadi vacant clean dilakukan hal tersebut supaya data yang berada di work list room attendant tersebut team leader mengetahui kamar tersebut sudah selesai dikerjakan dan siap untut di jual.

b) Setelah di lanjutkan dengan mengupdate jumlah data aminities dan linen yang di gunakan tamu per kamarnya, dilakukan hal tersebut supaya bagian departemen house keeping mengetahui pemakaian dan pengeluaran yang harus di keluarkan untuk aminities dan linen setiap bulannya.

\subsection{SOP PENANGAANAN CONPLAINT DI DELUXE ROOMTHE HAVEN SUITES CANGGU, BALI}

Complaint adalah perasaan yang timbul karena suatu hal yang membuat tamu merasa tidak puas, diantaranya salah satu contoh complaint yang sering terjadi di The Haven Suites Canggu, Baliyaitu:

A. Terdapat noda kuning atau sobek di duver cover.

1. Cara menanggulanginya adalah:

a) Menjaga eye contact dengan memperhatihan hal yang diucapkan.

b) Jangan sekali-kali memotong pembicaraan. 
c) Perlihatkan sikap fokus dengan apa yang di ucapkan oleh tamu.

d) Positif body language dan tunjukan listening skill

e) Bila tamu menghubungi bagian order taker selanjutnya dihubungkan dengan team leader dan dari team leader akan memberitahukan room attendant yang membersihkan di lantai tersebut walaupun memakan waktu yang banyak.

2. Cara penyelesaiannya adalah:

a) Apabila room attendant yang sedang mengerjakan kamar lain, maka pihak house keeping biasanya menghubungi petugas yang bertanggungjawab atas kebutuhan kamar dan tamu (runner) untuk mengerjakan hal tersebut.

b) Setelah selesai masalah tersebut maka pihak house keeping meminta maaf atas ketidak nyamanan selama tamu menginap.

B. Kamar berlum siap atau masih vacant dirty (VD)

1. Cara menanggulanginya adalah:

a) Menjaga eye contact dengan memperhatihan hal yang diucapkan.

b) Jangan sekali-kali memotong pembicaraan.

c) Perlihatkan sikap fokus dengan apa yang di ucapkan oleh tamu.

d) Positif body language dan tunjukan listening skill anda

e) Mendengarkan keluhan tamu dan mencatatnya

2. Cara menyelesaikan masalah tersebut karena tidak secara langsung complaint tamu ke bagian house keeping namun ke bagian front office, maka disini ada dua tipe penyelesaian di dua departemen yaitu: 


\section{Front office}

a) Memberikan penjelasan dan janji kepada tamu bahwa kamar yang akan di tempati akan selesai sebentar lagi atau paling lama 30 menit

b) Setelah itu bagian departemen front office biasanya mengalihkan tamu ke Cafe, Club, atau ke restoran untuk makan sebagai permohonan minta maaf, sambil menunggu kamar siap untuk di tempati

\section{House keeping}

a) Setelah selesai masalah tersebut karena tingkat huniannya sedang tinggi, maka pihak house keeping biasanya memberikan surat permohonan maaf dan memberikan welcome fruits.

b) Mencatat tanggal complaint untuk menjadi bahan perbaikan kedepanya.

\section{PENUTUP}

Berdasarkan pengamatan peneliti selama melaksanakan penelitian di The Haven Suites Canggu, Bali, maka peneliti mencoba memberikan kesimpulan sebagai berikut:

1. Tugas dan tanggung jawab room attendant di deluxe room The Haven Suites Canggu, Bali dilaksanakan sesuai dengan standar operasional prosedur (SOP). Adapun tugas dan tanggungjawab dalam hal membersihkan kamar dibagi menjadi dua shift yaitu morning shift dan evening shift dalam pelaksanaannya tersebut terdapat sedikit perbedaan yaitu:

a) Morning shift melakukan kegiatan membersihkan kamar di mulai dengan persiapan, pembersihan, dan pengecekan atau closing. 
b) Evening shift pekerjaannya tidak terlalu banyak maka sebelum room attendant evening shift mendapatkan work list nya, di haruskan membantu dahulu pekerjaan morning shift yang vacant dirty atau kamar-kamar yang belum di selesaikan oleh morning shift.

c) Setelah selesai room attendant melaksanakan evening shift, dilakukan pembersihan kamar yang di dalamnya hanya melakukan pemindahan aminities dan linen yang bertujuan untuk mempermudah tamu (turn down).

2. Terdapat kendala di dalam membersihkan deluxe room di The Haven Suites Canggu, Baliyaitu:

a) Room attendant setelah melakukan pembersihan kamar harus mengisi beberapa form di antaranya room discrepancy yang seharusnya diisi oleh team leader

b) Room attendant ditugaskan untuk membersihkan kamar paling sedikit 2 sampai 3 lantai dengan 1 room attendant dengan masing-masing mendapatkan 16 sampai 35 kredit yang harus di kerjakan pada saat high season yang standarnya harus dikerjakan oleh 2 orang room attendant.

Berdasarkan pengamatan peneliti selama melaksanakan penelitian, berikut ini peneliti memberikan saran-saran kiranya dapat diterima bagi pihak Hotel khususnya House keeping departemen sebagai berikut:

a) Agar seorang room attendant tidak dibebankan lagi dengan form discrepancy, karena sudah ada work list yang menjadi acuan room attendant dalam membersihkan kamar.

b) Agar menambah tenaga kerja daily worker yang mempunyai basik perhotelan untuk membantu room attendant dalam menangani 
kondisi kamar yang dalam keadaan high season sehingga meringankan beban kerja room attendant.

c) Sebaiknya penanganan complaint tamu haruslah di tangani secara cepat dan propesional tanpa membedakan masalah itu besar atau kecil, yang akan bermanfaat bagi citra The Haven Suites Canggu, Bali apabila hal-hal tersebut dilakukan.

\section{DAFTAR PUSTAKA}

Agusnawar. 2000. Operasional tata Graha Hotel: Hotel Housekeeping Operational. Jakarta: Gramedia Pustaka Utama

Arikunto, Suharsimi, 2006, Prosedur Penelitian Suatu Pendekatan Praktek, Jakarta: Rineka Cipta.

Bagyono. 2008. Problem Solving \& Terminologi Housekeeping Hotel. Bandung: Alfabeta.

Bagyono. 2009. Manajemen Housekeeping Hotel.Alfabeta

Bataafi, Wisnu HS Al. 2006. Housekeeping Department-Floor \& Public Area Job Description \& Strandard Operating Procedure. Bandung: Alfabeta.

Damayanti dan Yulianto. 2014. Peranan House keeping dalam Menangani Komplain untuk Memberikan Kepuasan Tamu Di Mawar Asri Hotel Jogja. Khasanah Ilmu Vol V No. 2 September 2014

Fauzan. 2015. Peranan Room Attendant Di House Keeping Department Dalam Upaya Meningkatkan Pelayanan Kepada Tamu di Sala View Hotel Di Solo. Fakultas Ilmu Budaya Universitas Sebelas Maret Surakarta

Moeloeng J Lexy. 2014, Metodologi Penelitian Kualitatif. Bandung: Remaja Rosdakarya

Nazir. 1986. Metode Penelitian. Jakarta: Rineka Cipta.

Rumekso. 2005. Housekeeping Hotel-Floor section. Yogyakarta: Andi Offset.

Satori, Djaman dan Aan Komariah. 2010. Metologi Penelitian Kualitatif. Canggu: Alfabeta

Setyaningrum, Ari. 2007. Pengaruh Ketidakpuasan Konsumen Dan Variety Seeking Terhadap Keputusan Perpindahan Merek. Jurnal Telaah Manajemen, Vol. 2, No. 2 November 2007

Soenarno, Adi. 2006. Front Office Management. Yogyakarta: Andi Offset. 
Sugianti. 2017. Faktor-Faktor Yang Mempengaruhi Kinerja Room Attendant Di Hotel Grand Central Pekanbaru. Jom Fisip Vol. 4 No. 2 - Oktober 2017

Sugiarto. Endar. 1996. Pengantar Akomodasi Dan Restoran, Jakarta: PT. Gramedia Pustaka Utama.

Sugiyono. 2007. Metode Penelitian Bisnis. Bandung: CV Alfabeta

Sulastiyono, Agus. 2011. Menejemen Penyelenggaraan Hotel, Seri Menejemen usaha Jasa Sarana Pariwisata dan Akomodasi. cetakan ke enam, Canggu: Alfabeta.

Umar, Huesin. 2009. Metode Riset. Jakarta: PT. Gramedia Pustaka Utama.

\section{PROFIL PENULIS}

Made Handijaya Dewantara, SST.Par.,M.Par.,M.Pro. lahir di Singaraja-Bali, 5 Mei 1989. Ia menempuh pendidikan sarjana pariwisata di STP Nusa Dua Bali, dan lulus tahun 2011. Menempuh pendidikan Master di Universitas Udayana-Bali, dan Universite Paris 1-Pantheon Sorbonne Perancis, dan lulus pada tahun 2014. Setelah menempuh pendidikan S2-nya, ia kemudian terjun di industri perhotelan sebagai Operational Manager, di Bali Villas Management, yang merupakan hospitality management company di bidang pengelolaan resort dan villa. Hingga saat ini, ia memiliki pengalaman mengajar di bidang Manajemen Perhotelan, Manajemen Pariwisata, Ekonomi Pariwisata, Manajemen Tata Graha, Manajemen Kantor Depan, dan Kewirausahaan. Selain menjadi dosen sekaligus Kaprodi D4 Manajemen Perhotelan di Politeknik Internasional Bali, ia juga mengembangkan bisnis di bidang konsultan hospitality, villa, dan akomodasi wisata. 